\title{
Thinking about the un-thinking
}

\author{
Geoff Norman
}

Published online: 24 January 2015

(C) Springer Science+Business Media Dordrecht 2015

This issue could almost lay claim to being a special issue about all those things that aren't supposed to matter in learning but do. Although emotions and interpersonal skills have been recognized as an essential component of competence for any health professional, they are rarely integrated into an overall perspective on the what and how of learning. At admissions, we speak of assessing "non-cognitive" (un-thinking?) skills. We hold separate courses in communication skills, frequently taught by professionals like social workers and clinical psychologists, whose professional qualifications are unassailable, but who reinforce the notion that this is a separate domain, detached from the mainstream. We speak of the "hidden curriculum", which all too often reinforces a paternalistic and aloof role for the professional.

Our research endeavours reinforce this dissociation. Cronbach (1957) first noted two solitudes within psychology, where one group-the correlationists-studying clinical, developmental, intelligence, focused their research on individual differences and the other, the experimentalists, eschewed any hint of individual attributes, having only recently graduated from dogs, mice and pigeons to undergraduate psychology students. In health sciences education, there is an analogous dichotomy. People like me do psychometrics on tests, and while we may look for indices of individual differences, they lie exclusively in the "cognitive" domain. The new movement in "Science of Learning, Science of Instruction," championed by cognitive and educational psychologists like Bjork, Roediger, Dunlosky, who have moved from cognitive psychology into mainstream education and health professions education, speak of human learning as if we're all pretty well wired the same, with more or less the same working memory and long-term memory, and certainly nothing of relevance outside the prefrontal cortex. It's as if we think about learning of emotions, or learning or emotions, but never learning and emotions.

G. Norman $(\bowtie)$

McMaster University, Hamilton, ON, Canada

e-mail: norman@mcmaster.ca 
It was actually there all along. This was brought home to me abruptly a couple of years ago when we were having a coffee discussion about anxiety and learning, and we all were dimly aware that it was likely some kind of U-shaped curve where too little or too much anxiety led to sub-optimal learning. We speculated about whether anyone had studied it. At which point, Lawrence Grierson, then a new colleague from kinesiology, reached in his backpack and pulled out an undergraduate kinesiology textbook, then turned to the page describing the Yerkes-Dodgson law, ca. 1910 (Cohen 2011), which precisely describes this curve!

Well, we are seeing some new frontiers in education, where we are actively attempting to examine the role of emotions in learning and competence. There are six papers in this issue that examine various aspects of personality and emotion and their role in achieving competence. Remarkably, these were not selected as a special issue but simply were in the regular sequence of papers based on time of acceptance. So let's briefly have a look at the range of topics:

Toto et al. (2014) looks at empathy across the continuum of undergraduate education and find, counter to many studies, that empathy actually increased in the final year. This adds fuel to an ongoing controversy that these authors dissect in their discussion. It is simply not clear whether empathy does or does not decline with increasing education. Toto went further, looking at both cognitive (perspective-taking) and affective components of empathy and looking at the relationship to stable personality characteristics.

Hancock et al. (2014) also takes on a longstanding issue in health profession education-tolerance of ambiguity. It is frequently argued that health professionals, particularly in primary care, must have a high tolerance for uncertainty and ambiguity. Hancock set out to devise a scale to measure tolerance, so the discussion could be put on an empirical basis. Like Toto, their primary interest was change with education; what emerged was that foundation year (first postgraduate year) trainees had higher tolerance than medical students. Not surprising, perhaps, but also encouraging.

Three papers examine the relation between measures of personality and emotion and student learning achievement. Zhou et al. (2014) looks at predictors of academic success, but instead of the usual grades, MCAT and so on, he looks at psychosocial variables-selfconcept, faculty interaction, and homework, all of which are significant predictors. Madjar et al. (2014) examines the relationship between frustration tolerance and perceived psychosocial abilities. Both studies use structural equation modeling, which is a powerful statistical method to test theoretical relationships between variables. Raat et al. (2014) looks at the relationship between social comparisons (using experience of others) and distress, measured by the General Health Questionnaire. Again, a sophisticated statistical strategy, MANOVA, was used to examine relationships.

Finally, LeBlanc et al. (2014) contributed a wide ranging review of the role of emotions in cognition, examining how emotion influences various aspects of cognition-perception, memory and reasoning, linking evidence from neuroscience and psychology. Impressively, she critically examines various models and dimensions of emotion, and does not consider it as a unidimensional bimodal state.

The papers are astonishing in their depth, sophistication and diversity, not just in the range of questions posed and the statistical elegance of the methods, but also in geography-the U.S., the U.K. Israel, Netherlands, Canada and China. Together they point to a new direction in spanning the longstanding separation between cognition and affect. 
You might notice that this issue occupies more horizontal space on your bookshelf than usual. As a consequence of increased submissions, we have more and more articles ready for publication. Consequently we have decided to increase the size of each issue in order to keep the publication queue within limits.

\section{References}

Cohen, R. A. (2011). Yerkes-Dodson law. In J. S. Kreutzer, J. DeLuca \& B. Caplan (Eds.), Encyclopedia of clinical neuropsychology (pp. 2737-2738). New York: Springer.

Cronbach, L. J. (1957). The two disciplines of scientific psychology. American Psychologist, 12, 671-684.

Hancock, J., Roberts, M., Monrouxe, L., \& Mattick, K. (2014). Medical student and junior doctors' tolerance of ambiguity: Development of a new scale. Advances in Health Science Education. doi:10.1007/ s10459-014-9510-Z.

LeBlanc, V. R., McConnell, M., \& Monteiro, S. D. (2014). Predictable chaos: A review of the effects of emotions on attention, memory and decision making. Advances in Health Science Education. doi:10. 1007/s10459-014-9516-6.

Madjar, N., Kushnir, T., \& Baschner, Y. G. (2014). Communication skills training in medical students: Do motivational orientations predict changes over time in psychosocial attributes? Advances in Health Science Education. doi:10.1007/s10459-014-9506-8.

Raat, A. N., Schonrock-Adema, J., van Hell, E. A., Kuks, J. B. M., \& Cohen-Schotanus, J. (2014). Student distress in clinical workplace learning: Differences in social comparison behaviours. Advances in Health Science Education. doi:10.1007/s10459-014-9513-9.

Toto, R., Man, L., Blatt, B., Simmens, S., \& Greenberg, L. (2014). Do empathy, perspective-taking, sense of power and personality differ across undergraduate education and are they inter-related? Advances in Health Science Education. doi:10.1007/s10459-014-9502-z.

Zhou, Y. X., Ou, C. Q., Zhao, Z. T., Wan, C. S., Guo, C., Li, L., \& Chen, P. Y. (2014). The impact of selfconcept and college involvement on the first-year success of medical students in China. Advances in Health Science Education. doi:10.1007/s10459-014-9515-7. 